"This is a pre-copyedited version of a contribution published in Ahram, T., Taiar, R., GremeauxBader, V., \& Aminian, K. (Éds.). Human Interaction, Emerging Technologies and Future Applications II: Proceedings of the 2nd International Conference on Human Interaction and Emerging Technologies: Future Applications (IHIET - AI 2020), April 23-25, 2020, Lausanne, Switzerland. Published by Springer International Publishing AG. The definitive authenticated version is available online via http://dx.doi.org/10.1007/978-3-030-44267-5_60"

\title{
Evaluation of gerontechnologies: a support to decision making and prescription
}

\author{
Djamel Aissaoui ${ }^{1}$, Javier Barcenilla ${ }^{2}$ \\ ${ }^{1}$ School of Health Sciences, HES-SO Valais-Wallis, Agasse 5, Sion, Switzerland \\ ${ }^{2}$ Université de Lorraine - Metz, PErSEUs, Ux Lab. Île du Saulcy, 57045 Metz, France. \\ Djamel.aissaoui@hevs.ch ; javier.barcenilla@univ-lorraine.fr
}

\begin{abstract}
In addition to usual Information and Communication Technology (ICT) devices, things are becoming "therapeutic" and can be dedicated to the specific needs of aging. However, because there is a diversity of senior impairments, one must diagnose needs, expectations, abilities or skills of seniors in order to provide the best adapted functions and usages. Moreover, these devices must be evaluated to determine their real potential and effectiveness. This paper discusses how to choose the best fit between a health technology and age-related deficits, and how we can assess the results of this fit. In this context we will use a tool and methodology called "Design for Adapted Devices" (i.e. DAD). DAD tries to develop adaptable systems based on the comprehensive diagnosis of human deficits and needs taking into account several dimensions of user diversity like skills and abilities (e.g. motor, cognitive skills, etc.), and measure deficits that "modulate users" performances (e.g. social support, experience, strategies, etc.). DAD gives prospective data to define future smart things and provides information about technology assessment.
\end{abstract}

Keywords: Health Technology Assessment · Universal design · senior needs smart things · impairments diagnosis · Human-systems Integration ·

\section{$1 \quad$ Introduction}

When we talk about seniors, we are talking about a broad category of people who differ in many ways. This may include people who are still active or retired, with or without deficits, living alone or with their families, having the status of caregiver or assisted, living at home or in a retirement home, different in age, etc. This has a generational effect in terms of attitudes, skills, desires, etc. Each of these categories has specific needs.

The accelerated aging of the population reinforced by the lack of medical staff will lead, in the coming years, to an extremely difficult situation when referring to health care system

In parallel to these two phenomena, a third one related to the "fast development of digital technologies" seems to allow interesting alternatives fulfilling the requirements 
of elderly people, caregivers and professionals. Digital technologies seem to play a key role on some signs of aging by helping, assisting, stimulating and rehabilitating. These new possibilities will improve the quality of life and autonomy of elderly population (i.e. primary users) and increase the capabilities of the professionals or caregivers (i.e. secondary users) for caring, monitoring and diagnosis.

However, these new opportunities have limited success among these two categories of users. Reasons for this are diverse. Manufacturers producing information and communication technologies and those manufacturing technical aids often ignore the needs of these categories of people: those arising from their real perceptual, motor, attention, memory, cognitive and social capacities. The reasons for this are multiple: economic, lack of knowledge about user-center design, lack of research on user feedback and different contexts of use, stereotypes of designers about the elderly and more specifically a lack of information and understanding of people with special needs $[1,2]$.

There is hence a clear need to diagnose the disabilities and the needs precisely, to find adapted solutions between the technological potentials and the difficulties of people and finally, to evaluate solutions in order to generalize results.

\section{Health technologies - gerontechnologies and their assessment}

"Health technology" is a generic term that includes many goods and services that can be extremely different, such as pharmaceuticals, supplies, equipment, medical devices, public health programs, support, management and organizational systems used for prevention, screening, diagnosis, treatment, and rehabilitation [3]. In addition, the shape of these technologies can be varied with more or less sophisticated objects, ranging from fall sensors, to connected pill dispensers, or other geolocation and actimetric technologies, etc.

Within these health technologies, we can distinguish a sub-division: the gerontechnologies. The field of study assigned to it combines research on epidemiological and demographic indicators related to ageing (i.e. increase in life expectancy, prevalence and incidence of diseases, etc.), as well as the design and improvement of health technologies; the objective of which is to compensate for deficits or facilitate the activities of older people.

The gerontechnologies are based on two major areas of research that are constantly and rapidly evolving. On the one hand, the medico-social and paramedical sciences (i.e. medicine, geriatrics, psychology, physiology, biology, etc.), and on the other hand, the more design-oriented sciences (i.e. ergonomics, computing, engineering, architecture, etc.).

The scope of these ageing technologies is extremely diverse (e.g. health, housing and domestic life, mobility and transport, management, leisure, safety, etc.), which further complicates its organization and evaluation possibilities. But the objective is the same, that is, to create a technological environment that respects the needs of older people by allowing them to integrate into and participate in social life and remain at home as long as possible in health and safety. It is therefore essential to be able to test these devices and to have clear and objective indicators concerning effectiveness, benefits/risks, usability, etc. 
However, when trying to evaluate the concrete contributions of these technologies opinions diverge. For example, the Parrot social robot system (i.e. Socially assistive robots: SARs) aims to improve social interactions (i.e. therapists, family network, elderly people with dementia) and to encourage people to engage in physical and cognitive activities. When studying the actual contributions of this technology, the data are contradictory. Some report beneficial results $[4,5]$, while others are more mixed [6].

It is difficult to obtain reliable information on the real utility of a technology for several reasons:

First, the use of information synthesis such as systematic review and, where possible meta-analysis, are interesting sources for evaluation and selection of one device over another. However, they suffer from two problems: a lack of consensus because methodologies and indicators are too different, making the comparison complex [7], and the difficulty to access to the "grey literature", important in this field (e.g. company reports, assessments by private companies, etc.) because of project confidentiality and fear of industrial spying.

Secondly, publication and over-interpretation biases in the available studies can also be suspected. Indeed, a conflict of interest can legitimately be questioned, either when industry uses private evaluation companies or when researchers must find private funds for their work. Moreover, some authors $[8,9]$ notes that several surveys have shown significant conflicts of interest in the evaluation of medical systems.

Today, there are structures dedicated to the design and experimentation of products for the elderly. University structures such as senior living-labs, user laboratories, or centers of expertise, and private national or international consulting firms, such as the Health Technology Assessment International (i.e. HTAi) and the International Network of Agencies in Health Technology Assessment (i.e. INAHTA), which collaborate with the WHO [10] and propose to test technologies for ageing. Nevertheless, these actors need validated and standardized methods, approaches and tools to obtain more reliable results that could be generalize.

However, from the point of view of evaluation methods, a number of difficulties can be observed in their implementation. For example, gerontechnologies - even when they claim to be therapeutic - are not considered as medical treatments and they don't need to meet the requirements of regulatory agencies (e.g. Food and Drug Administration or European Medicines Agency, etc.) before being placed on the market; even if Europe, unlike the United States, requires a certificate of conformity ("CE" label) for marketing delivered on the basis of a "technical file" which must contain some clinical data, but these data are not comparable to those required for a drug (i.e. clinical trial). Furthermore, some technologies do not take the name "therapeutic" and thus escape these obligations.

It could then be considered that clinical trials should be a standard for evaluating gerontechnologies and to obtain EBPs; but still, the length and complexity of these methodological mechanisms could be considered as time-consuming and too expensive. For example, the evaluation of "fall sensors" carried out by Lachal [11] in his thesis work is relevant, but it corresponds to a too high human and financial cost (i.e. seven health professionals mobilized and 167 patients over a one-year period at a cost of 337 Keuros).

It is therefore essential to conceive efficient methods and tools that allow a valid and clear assessment of technology. 


\section{A methodology and a tool for assessing needs of seniors and guide conception of gerontechnologies}

We have recently developed and validated a computerized diagnostic tool and a method for assessing the needs of seniors and to evaluate technical systems and services for seniors $[12,13]$. The tool designed "DAD" (i.e. Design for Adapted Devices) is a computer system (i.e. software) whose objective is to facilitate and standardize diagnostic procedures for people with special needs in loss of autonomy, and to analyze their needs according to the tasks and activities performed in everyday life.

The originality and effectiveness of this method derives from the fact that it allows for simultaneous measurement and integration, the diagnosis of the capacities required to use a system, product or service, and the diagnosis of the person's capacities and deficits. The pairing of these two diagnoses allows for an integrative and proactive approach to develop technical solutions for seniors, as a function of their needs.

The DAD diagnosis grid is made of 10 dimensions. Six dimensions measure deficits (motor skills and physical resistance, Perceptual abilities, memory and attention, language, temporo-spatial orientation, reasoning, planning and problem solving), while four dimensions evaluate those factors that modulate performances (e.g. social support, experience with ICT, interest and acceptability en effects of medication on the ICT supported activity, strategies, etc.). Each of these dimensions comprehends subdimensions for further specifications [12]. While making a diagnosis of a person's abilities, "modulating factors" must be evaluated because they could influence in a positive or negative way a person's performance. Each ability or skill is evaluated on a Likert scale from 1 to 5 , where 1 means an absence of capacity or ability and 5 that the person retains his or her capacities.

In addition, and to establish which deficit should be compensated or rehabilitate for seniors, experts with the system or with the technical domain are submitted to the same grid, in order to evaluate the skills required to use the ICT device or service for activities in everyday life. The gap between a person's assessment and the expert assessment provides what needs to be improved (1).

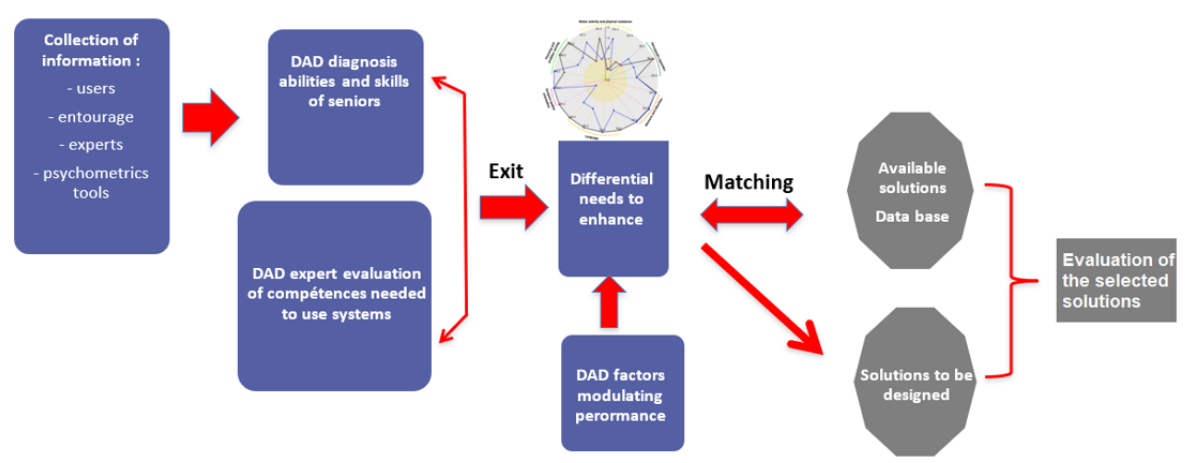

Figure 1. Design for Adapted Devices method for evaluating deficits and needs of seniors and for providing adapted solutions 
DAD has been designed in a multidisciplinary approach and has been evaluated by geriatricians, doctors, psychologists, ergonomists, nurses, etc. It allows evaluating the capacities of an individual at a time " and their evolution, the creation of population profiles in certain structures, as retirement homes, and to assess the skills needed to use assistive technologies. DAD allows the results obtained to be presented in the form of a statistical table or in a graphical radar chart format, which permits to visualize directly the deficits to be compensated (see figure 2).

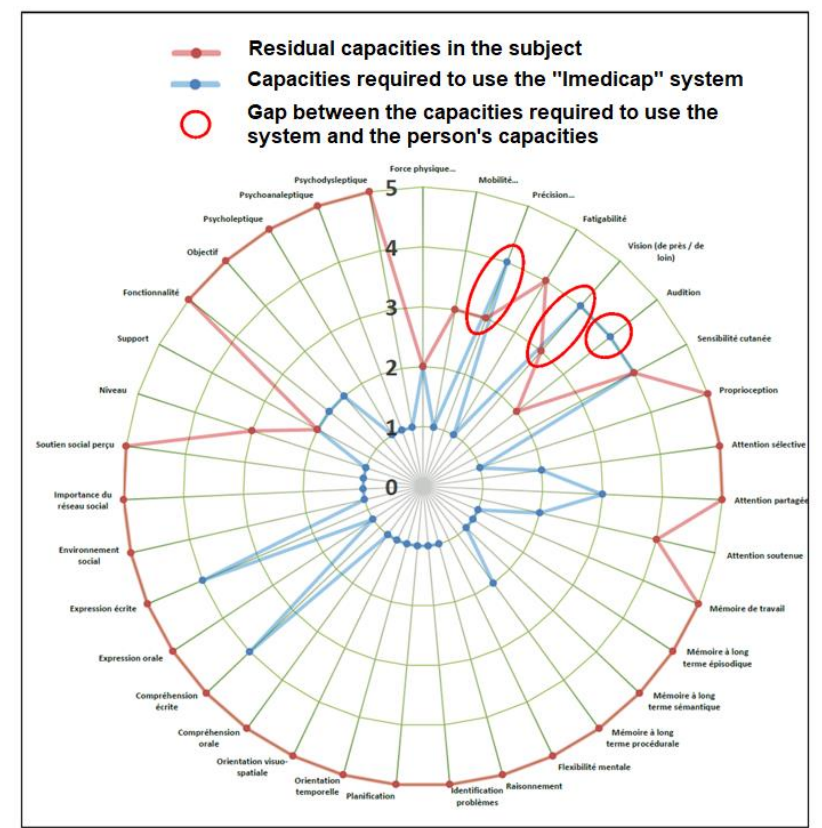

Figure 2. Differential result between the abilities preserved or deficient in a person and abilities required for using a technical device (pill dispenser "Imedipac")

As we have said before, DAD makes it possible to carry out multiple analyses and compare the adequacy between the residual capacities of people and the systems proposed; or to compare the adequacy of several technical systems intended to provide the same functionalities.

\section{Conclusion}

Several reports have pointed out important barriers to development, acquisition, use and acceptance of technical aids for seniors with impairments. Among these, lack of information about needs of users, equipment reliability, the need to strengthen monitoring and evaluation of aids proposed, the need for a global and personalized approach to assist seniors, etc. Most of these barriers reflect shortcomings in ergonomics aspects of tools but also the absence of a coordinated, coherent approach to develop aids. Often this is due to intervention of multiples partners who do not share the same frames, references and Knowledge. 
Among others, one main purpose of DAD is to propose a standardized tool for helping practitioners concerned ergonomics field that have insufficient knowledge and methods for carrying out this process.

Providing solutions is figuring out how to adapt ICT technologies to the seniors' profiles. In terms of innovative solutions, since DAD was defining the users' requirement profile, a module configuration that you can enable / disable can optimize the adaptation of the interface of the ICT technology to each senior.

\section{References}

1. Lecomte, D.: Aides techniques aux personnes handicapées : Situation actuelle, données économiques, propositions de classification et de prise en charge. (2003).

2. Rialle, V.: Technologies nouvelles susceptibles d'améliorer les pratiques gérontologiques et la vie quotidienne des malades âgés et de leur famille. Ministère de la santé et des solidarités (2007).

3. Les processus d'évaluation des technologies de la santé : règles de base, https://www.eupati.eu/fr/evaluation-des-technologies-de-la-sante/les-processus-devaluation-des-technologies-de-la-sante-regles-de-base/, last accessed 2019/06/22.

4. Cotten, S.R., Ford, G., Ford, S., Hale, T.M.: Internet use and depression among retired older adults in the United States: A longitudinal analysis. J. Gerontol. B. Psychol. Sci. Soc. Sci. 69, 763-771 (2014). https://doi.org/DOI: 10.1093/geronb/gbu018.

5. Hogeboom, D.L., McDermott, R.J., Perrin, K.M., Osman, H., Bell-Ellison, B.A.: Internet use and social networking among middle aged and older adults. Educ. Gerontol. 36, 93-111 (2010). https://doi.org/10.1080/03601270903058507.

6. Turkle, S.: Alone together: Why we expect more from technology and less from each other. Basic books (2012).

7. Parlement Européen, Conseil de l'Union Européenne: Règlement (CE) no 765/2008 fixant les prescriptions relatives à l'accréditation et à la surveillance du marché pour la commercialisation des produits, OJ L 218, https://eur-lex.europa.eu/legal-content/FR/TXT/?qid=1415011406506\&uri=CELEX:32008R0765.

8. Féry-lemonnier, E.: L'évaluation des technologies médicales. adsp. 28-33 (2002).

9. Kiefer, B.: Conflits dans les conflits d'intérêts. Rev. Médicale Suisse. 11, 1368-1368 (2015).

10. World Health Organization ed: Evaluation Des Technologies De La Sante: Dispositifs Medicaux. Organisation mondiale de la Santé, Switzerland (2012).

11. Lachal, F.: Les nouvelles technologies: une réponse aux effets physiologiques du vieillissement et des maladies liées au grand âge, (2015).

12. Aissaoui, D.: Diagnostic des déficits et des besoins liés au vieillissement: apports pour la conception de gérontotechnologies, (2018).

13. Barcenilla, J., Tijus, C., Aissaoui, D., Brangier, E.: Design for adapted devices : an evaluation tool of smart things for seniors. In: International Conference on Universal Access in Human-Computer Interaction. pp. 3-11. Springer (2013).

"This is a pre-copyedited version of a contribution published in Ahram, T., Taiar, R., GremeauxBader, V., \& Aminian, K. (Éds.). Human Interaction, Emerging Technologies and Future Applications II: Proceedings of the 2nd International Conference on Human Interaction and Emerging Technologies: Future Applications (IHIET - AI 2020), April 23-25, 2020, Lausanne, Switzerland. Published by Springer International Publishing AG. The definitive authenticated version is available online via http://dx.doi.org/10.1007/978-3-030-44267-5_60" 